\title{
Knockdown HOXB7 suppresses the proliferation, migration and invasion in Renal cell carcinoma cells
}

\author{
Zhang Huiwu', ${ }^{1}$ Li Tie $^{2^{*}}$ and Li Xiuli ${ }^{* *}$
}

*Correspondence: lixiulizhw@163.com

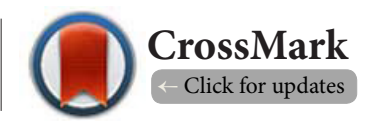

\begin{abstract}
${ }^{1}$ Cangzhou Central Hospital, Pediatrics department of Medicine, Xinhua West Road No. 16, Cangzhou, Hebei Province, China. ${ }^{2}$ Seventh People's Hospital of Hebei Province, Urology Surgery, Jungong Road No.389, Baoding City, Hebei Province, China. ${ }^{3}$ Cangzhou Central Hospital, Nephrology, Xinhua West Road No. 16, Cangzhou, Hebei Province, China.
\end{abstract}

\begin{abstract}
Purpose: HOXB7 is a gene of HOX gene family, which has been found to play a role in cancer cell proliferation, angiogenesis, and invasion. Due to its potential responsibility in cancer aggression, the main objective of this work was to investigate the expression in Renal cell carcinoma and the biological functions in Renal cell carcinoma cells.

Methods: To investigate HOXB7 expression in Renal cell carcinoma tissues and Renal cell carcinoma cell lines by using immunohistochemistry, Western blot and RT-PCR. Then we analyzed the relationship between HOXB7 expression and Renal cell carcinoma clinical parameters. The biological function of $\mathrm{HOXB} 7$ on proliferation, migration and invasion were investigated by CCK8 assays, Transwell and Matrigel assays, after knocking down the HOXB7 expression in Renal cell carcinoma cells with siRNAs.

Results: The results showed that HOXB7 protein was highly expressed in the Renal cell carcinoma tissues and cell lines. Down-regulating HOXB7 expression by siRNAs could suppress the proliferation, migration and invasion in Renal cell carcinoma cells. The HOXB7 expression was related to the poor differentiation by statistical analysis. Besides, HOXB7 was related to the patient prognosis by the survival analysis.
\end{abstract}

Conclusions: HOXB7 protein was expressed in the Renal cell carcinoma, which was related to the poor prognosis in Renal cell carcinoma patients. HOXB7 promoted the proliferation, migration and invasion in Renal cell carcinoma cells. Therefore, it may be a new marker to predict the prognosis and target to cure Renal cell carcinoma.

Keywords: HOXB7, Renal cell carcinoma, prognosis, migration, invasion

\section{Introduction}

Renal cell carcinoma (RCC) encompasses a heterogeneous group of cancers derived from renal tubular epithelial cells and is among the 10 most common cancers worldwide [1]. Localized RCC can be treated with partial or radical nephrectomy (removal of the kidney) [2], ablation (destruction of the malignant tissue with heat or cold) [3], or active surveillance (monitoring of tumor growth with periodic radiographic studies) [4]. Despite nephrectomy with curative intent, $\sim 30 \%$ of patients with RCC with localized disease eventually develop metastases, which require systemic therapies and are associated with high mortality. Therefore, early diagnosis is very important to Renal cell carcinoma patients, for early diagnosis helps to guide the medical strategy for the next step. To date, there are no effective methods to predict the prognosis in Renal cell carcinoma. Therefore, new tools should be developed for diagnosis and predicting prognosis for early stages of Renal cell carcinoma.

HOX genes encode a family of transcription factors that determines cellular identity during development [5]. The expression of HOX family is rarely found in the adult cells, but more and more studies confirmed that the HOX protein could also found in neoplasia and tumor tissues [6]. Human HOX genes now has been divided into two classes. In the class I, there are four paralogous clusters of HOX genes, which are defined as HOXA, HOXB, HOXC, and HOXD [7-9].

HOXB7 is a member of the HOXB family. As a transcription 
factor, the HOXB7 has functions to regulate specificity and stability of DNA-binding with cooperation with cofactors and other transcription factors. It has been found in some solid cancer including breast cancer, melanoma, colorectal cancer, such as, pancreatic ductal adenocarcinoma, oral squamous cell carcinomas, epithelial ovarian carcinoma, and lung cancer. Some studies showed that HOXB7 played an important role in cancer development and had a relation with tumor invasion and metastasis [10-14]. Some studies showed that its expression was related to predict the prognosis in solid cancers.

In this study, we found that HOXB7 was expressed in the Renal cell carcinoma tissues and related to the Gleason Scores, pathological grade and metastasis. Knocking down the HOXB7 expression decreased the proliferation, migration and invasion in Renal cell carcinoma cells.

\section{Methods and materials Clinical data}

The tissue microarray was bought from the Superchip Company (Shanghai, China. HKid-CRCC150CS-02). 65 cases.

\section{Immunohistochemistry}

After regular deparaffinization and rehydration, the tissues were blocked with normal goat serum (3\% in PBST, $0.05 \%$ Tween 20) for $30 \mathrm{mins}$ room temperature. The sections were washed out and then incubated with anti-human HOXB7specific antibody at dilution of 1:200 (Abcum company Cambridge, UK) overnight. The sections were washed with PBS and then incubated with second antibody for RT $1 \mathrm{~h}$.

The EnvisionTM ABC Kit for staining.

To evaluate the score of immunohistochemistry, we used the method below:

The percentage of stained cells per field was defined as the following: 0 , negative; $1,1-25 \% ; 2,26-50 \%$; and $3,51-100 \%$ of the cells. The staining intensity was scored on a 4 -tiered scale as follows: 0 , absence of signal; 1 , low-intensity signal (light brown); 2, moderate-intensity (brown); and 3, high-intensity signal (dark brown). The frequency score and intensity score were multiplied to obtain the score for each field.

\section{Western blot}

Protein was extracted from the prostate cancer cells and was measured by Pierce BCA Protein Assay Kit (Thermo Scientific, Rockford, IL). The membranes were incubated overnight at $4^{\circ} \mathrm{C}$ with the following primary antibodies' HOXB7(Abcum company Cambridge, UK). The reference protein was GAPDH. The immunocomplex was detected by using the ECL Plus kit (Amersham, Buckinghamshire,UK) and the band density was analyzed with Image software.

\section{RT-PCR}

Total RNA of Renal cell carcinoma cell lines 7860, ACHN and CAKI-I was extracted by TRIzol reagent and then reverse transcribed using RT-PCR Revert Aid, First Strand CDNA Synthesis
Kit (Thermo, Rockford, IL, USA) according to the manufacturer's instruction. Prime: Forward: 5'-ACCGACACTAAAACGTCCCTG-3' and Reverse: 5'- TTT GTTCTGGGAAGGCTCCG-3'.

GAPDH: (forward, 5'-CAAGGTCATCCATGACAACTTTG-3'; reverse, 5'-GTCCACCACCCTGTTGCTGTAG-3').

\section{Cell culture}

The Renal cell carcinoma cell line 7860 and ACHN was obtained from American Type Culture Collection (ATCC). Cells were cultured in RPMI 1640 (Hyclone, Logan, UT, USA) medium, supplemented with $10 \%$ fetal bovine serum (Hyclone, Logan, UT, USA) and at $37^{\circ} \mathrm{C}$ in a humidified atmosphere containing $5 \% \mathrm{CO}_{2}$.

\section{Cell proliferation assay}

The 7860 and ACHN cells were transfected with siRNA (50 $\mu \mathrm{g} / \mathrm{ml}$ ) in $96-w e l l$ plates and incubated at $37^{\circ} \mathrm{C}$. Cell proliferation was analyzed using the CCK8 Cell Proliferation Assay Kit (Invitrogen, USA). CCK8 reagent ( $5 \mu \mathrm{l}$ ) was added to each well and incubated for $2 \mathrm{~h}$. The number of viable cells was calculated by absorbance measurements at $450 \mathrm{~nm}$. Each condition was assessed in triplicate.

\section{Cell migration assay}

The migration assay was performed in a 24-well Transwell (Corning, USA) containing a polycarbonate filter $(8 \mu \mathrm{m}$ pore size). The T24 cells were counted as $10^{5}$ of each group to add in the Transwell chamber. Conditioned medium containing $10 \%$ fetal bovine serum was added to the bottom part of the chamber. The cells were incubated in a $5 \%$ carbon dioxide incubator at $37^{\circ} \mathrm{C}$ for $24 \mathrm{~h}$. After incubation, cells in the upper chamber that were attached but had not migrated were scraped off, and the migrated cells on the bottom of the filter were fixed with methanol and stained with hematoxylin. The number of cells was counted in at least 6 randomized fields under a microscope. Results were obtained from at least three individual experiments.

\section{Cell invasion assay}

The invasion assay was performed in a 24-well invasion (corning, USA) containing a polycarbonate filter ( $8 \mu \mathrm{m}$ pore size). The T24 cells were counted as $10^{5}$ of each group to add in the invasion chamber. Conditioned medium containing $10 \%$ fetal bovine serum was added to the bottom part of the chamber. The cells were incubated in a 5\% carbon dioxide incubator at $37^{\circ} \mathrm{C}$ for $24 \mathrm{~h}$. After incubation, cells in the upper chamber that were attached but had not migrated were scraped off, and the migrated cells on the bottom of the filter were fixed with methanol and stained with hematoxylin. The number of cells was counted in at least 6 randomized fields under a microscope. Results were obtained from at least three individual experiments.

\section{Results}

HOXB7 was expressed in the prostate tissues and cell lines In this study, the expression levels of HOXB7 in three rep- 
resentative Renal cell carcinoma cell lines (7860, ACHN and CAKI-I) were found with the methods of Western blot and RT-PCR. Immunohistochemistry showed that positive staining of was frequently located in the cytoplasm of cancer cells in Renal cell carcinoma tissues (56/60, 93.3\%). The normal prostate tissues were negative stained (Figure 1).

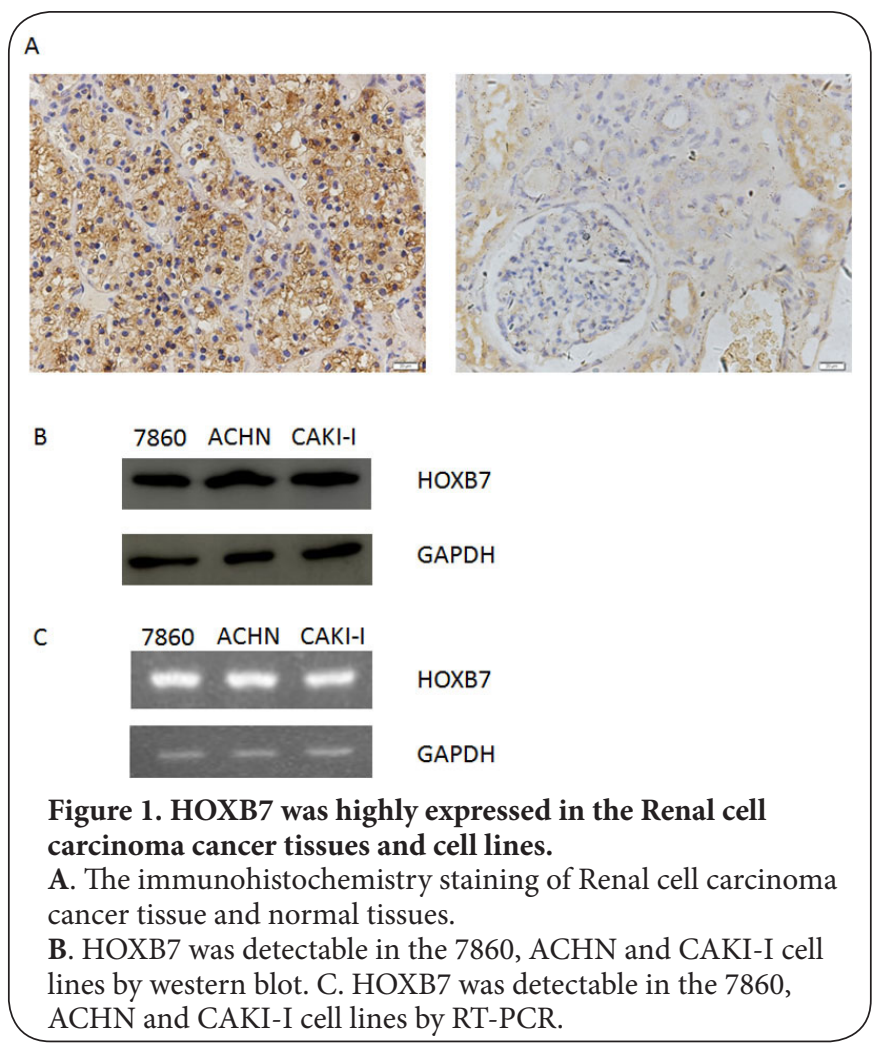

\section{Knocking down HOXB7 inhibited the proliferation ability}

Then we investigated the proliferation ability by using CCK8 arrays to determine whether HOXB7 could affect proliferation and survival in Renal cell carcinoma cells. The CCK8 assays results showed that in both 7860 and ACHN cells, the proliferation were suppressed significantly. In the 3th, 4th, 5th day, the growth rate was much higher in the siNC group than the siRNAs group, suggesting that the proliferation ability was affected by HOXB7 (Figure 2).

\section{Down-regulating the HOXB7 suppressed the migration and invasion}

The number of cells invading through the membrane in the siRNA group was significantly decreased from those in the negative control group in Transwell assays and Matrigel, suggested HOXB7 promote the prostate cancer migration and invasion (Figures 3 and 4 ).

\section{A}
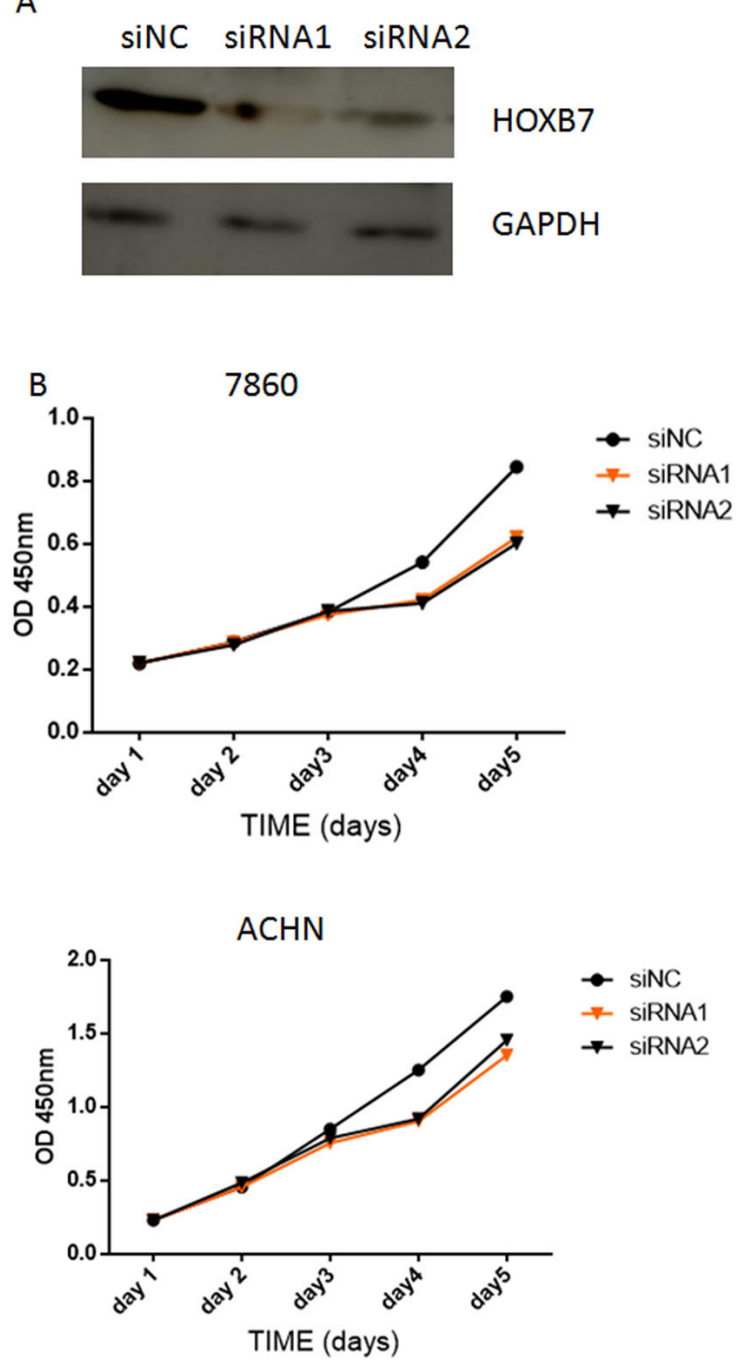

Figure 2. Knocking down HOXB7 reduced the proliferation of Renal cell carcinoma cancer cells. Using CCK8 assay the proliferation of Renal cell carcinoma cancer cells 7860 and ACHN was investigated after transfected with siRNA for 5 days.

A. HOXB7 expression of siNC, siRNA1, siRNA2 were tested by western blot.

B. The proliferation of Renal cell carcinoma cancer cells 7860 was investigated after transfected with siRNA for 5 days.

C. The proliferation of Renal cell carcinoma cancer cells ACHN was investigated after transfected with siRNA for 5 days.

HOXB7 was related to the poor differentiation in prostate cancer

In addition, we analyzed the immunohistochemistry data of the prostate cancer tissues of $\mathrm{HOXB7}$ and found a significant HOXB7 expression increased in the poor differentiation tissues, such as pathological grading and tumor size $(P<0.05)$. 

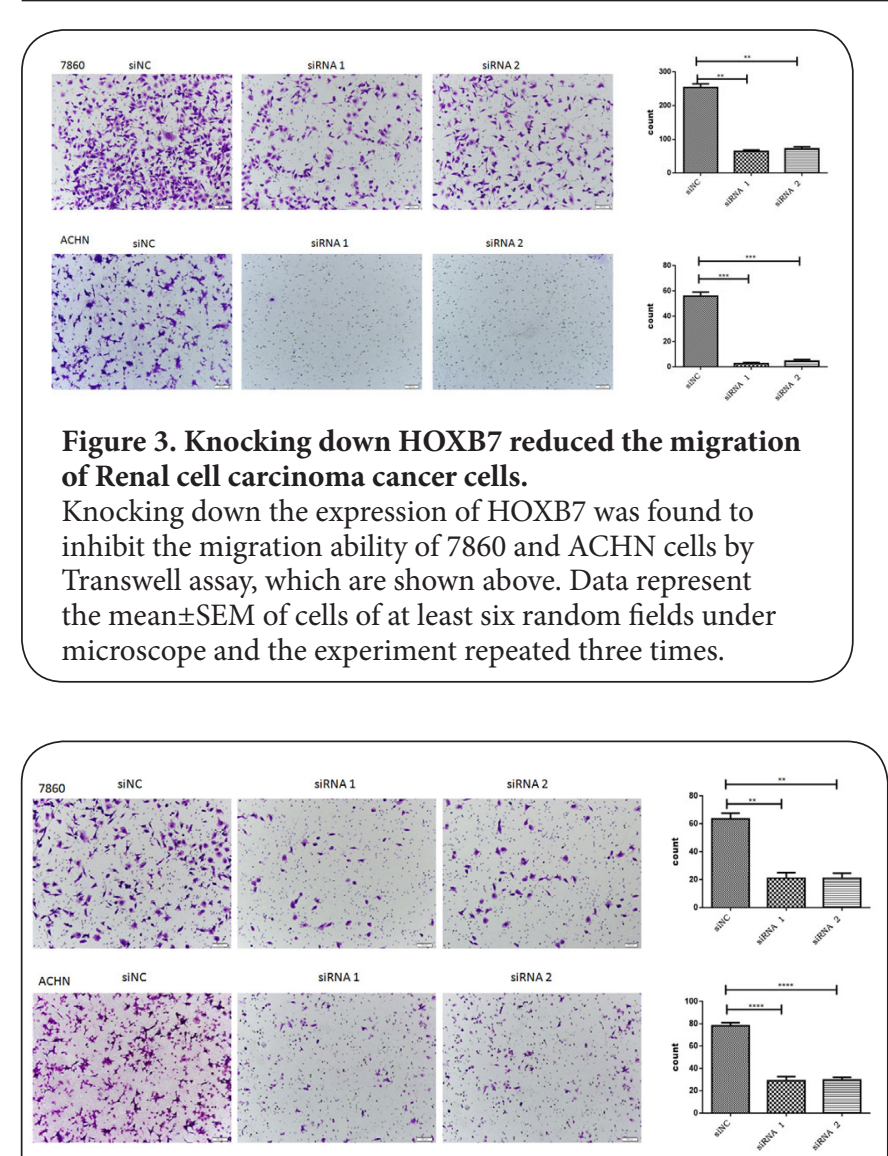

Figure 4. Knocking down HOXB7 reduced the invasion of Renal cell carcinoma cancer cells.

Knocking down the expression of HOXB7 was found to inhibit the migration ability of 7860 and ACHN cells by Matrigel assay, which are shown above. Data represent the mean \pm SEM of cells of at least six random fields under microscope and the experiment repeated three times.

HOXB7 expression had no relationships with Sex, Age and TNM stage (Table 1).

\section{Correlation between HOXB7 expression and survival in Renal cell carcinoma patients}

The 5.5-year overall survival of patients with Renal cell carcinoma patients was elevated according to the results of Kaplan-Meier analysis with HOXB7 expression. The survival rate of patients with weak positive (negative and "+") HOXB7 staining was significantly longer than that of patients with strong positive ("++" and "+++") HOXB7 staining $(P<0.05)$ (Figure 5). Cox multivariate analysis also showed that HOXB7 strong positive staining (hazard ratio $=4.765, \mathrm{P}=0.029$ ) and tumor size (hazard ratio $=2.670$ ) were risk factors of poor prognosis for Renal cell carcinoma patients (Table 2).

\section{Discussion}

In this study, we investigated the expression of the HOXB7 in Renal cell carcinoma tissues and Renal cell carcinoma cells
Table 1. Clinicopathologic Variables and Evaluation of HOXB7 Immunostaining in prostate cancer Tissues.

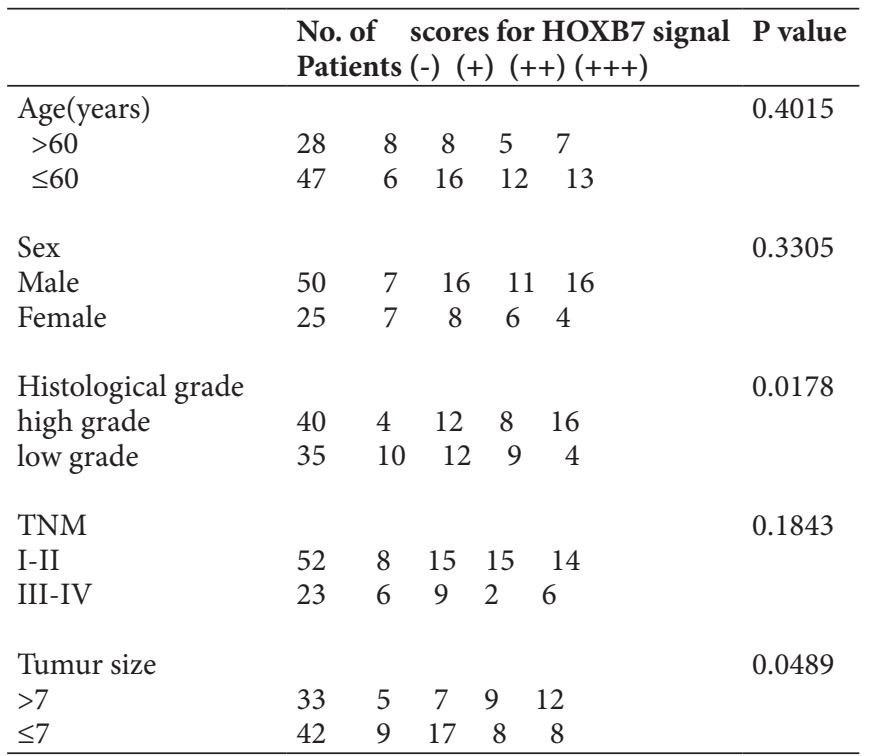

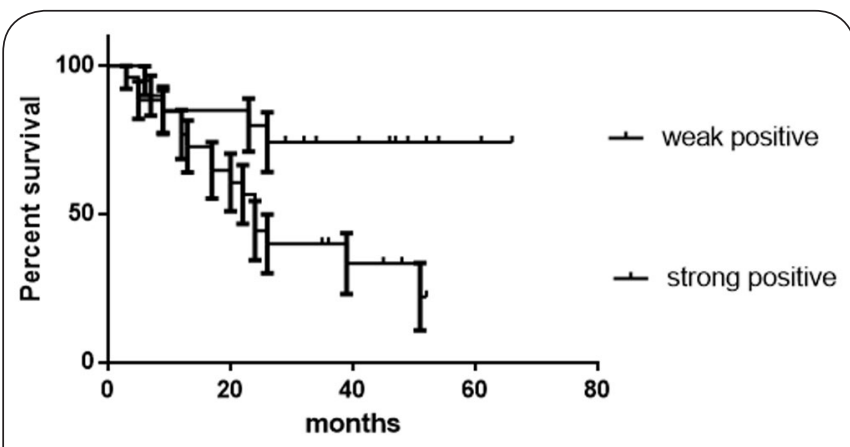

Figure 5. The correlation of HOXB7 expression and 5-year overall survival of patients with Renal cell carcinoma cancer patients.

Table 2. Cox multivariate analysis of prognostic factors in patients with Renal cell carcinoma.

\begin{tabular}{|c|c|c|c|}
\hline Characteristics & HR & $95 \% \mathrm{Cl}$ & P-value \\
\hline $\operatorname{Age}(\leq 60 />60)$ & 1.374 & $0.965-1.054$ & 1.155 \\
\hline Sex (Male/Female) & 1.564 & $0.451-2.514$ & 0.844 \\
\hline $\begin{array}{l}\text { Histologic grade } \\
\text { (High grade/Low grade) }\end{array}$ & 1.287 & $0.257-14.577$ & 0.257 \\
\hline $\begin{array}{l}\text { HOXB7 staining } \\
\text { (weak/strong) }\end{array}$ & 4.765 & $1.290-30.486$ & 0.029 \\
\hline $\begin{array}{l}\text { Tumor size } \\
(>7 / \leq 7)\end{array}$ & 2.670 & $0.158-2.086$ & 0.399 \\
\hline $\begin{array}{l}\text { TNM stage } \\
\text { (I-II/III-IV) }\end{array}$ & 2.211 & $0.236-5.193$ & 0.896 \\
\hline
\end{tabular}

CAKI-I, 7860 and ACHN. Knocking down the HOXB7 expression, the proliferation, migration and invasion ability of Renal cell carcinoma cell was significantly suppressed. Moreover, the HOXB7 expression was related to the poor prognosis in 
Renal cell carcinoma.

HOXB7 is found in many solid cancer tissues. In addition, several studies have found that HOXB7, as a potential marker of cancer metastasis, is significantly associated with metastases in cancer patients [15]. In this study, we demonstrated the expression in Renal cell carcinoma tissues and cell lines. By analyzing the expression of HOXB7, we found that HOXB7 expression was associated with pathological grade and metastasis and could be used as a marker for predicting the prognosis of patients with Renal cell carcinoma. It was also included in the four gene diagnostic markers (CLDN4, HOXB7, TMSB4 and TTR) Cholangiocarcinoma of liver tissue with hepatocellular carcinoma and benign biliary liver disease.

In addition, we follow the biological behavior and HOXB7 expression. HOXB7 can reduce migration, migration and invasion after knockout of Renal cell carcinoma cells, suggesting that HOXB7 can promote migration, migration and invasion. In another study, knockout HOXB7 expression also inhibited the ability of breast cancer MCF-7 cells to proliferate, migrate and invade [16]. This result supports our work on Renal cell carcinoma HOXB7. In lung cancer, Chen and colleagues found that HOXB7 could promote faster tumor growth in lung cancer cells.

So far, some scholars have found a number of HOXB7-related cell signaling pathways, including VEGF, Ang2, GROa and IL8 and so on. It has recently been reported that HOXB7 regulates TGF $\beta$ signaling pathway $[17,18]$. Over-expression of HOXB7 induces TGF $\beta$, leading to increased cellular motility and increased aggressiveness. It is reported that HOXB7 repair DNA.

\section{Conclusion}

Knocking down HOXB7 expression inhibits the ability of Renal cell carcinoma to proliferate, migrate and invade. Strong positive staining of $\mathrm{HOXB7}$ is a risk factor for poor prognosis in patients with Renal cell carcinoma. We believe that HOXB7 may provide a new standard for the prognosis of patients with Renal cell carcinoma, and HOXB7 may be a new and valuable target for the development of treatment strategies.

\section{Competing interests}

The authors declare that they have no competing interests.

\section{Authors' contributions}

\begin{tabular}{|l|c|c|c|}
\hline Authors' contributions & ZH & LT & LX \\
\hline Research concept and design & $\checkmark$ & -- & -- \\
\hline Collection and/or assembly of data & -- & $\checkmark$ & -- \\
\hline Data analysis and interpretation & -- & -- & $\checkmark$ \\
\hline Writing the article & $\checkmark$ & -- & -- \\
\hline Critical revision of the article & -- & -- & $\checkmark$ \\
\hline Final approval of article & -- & $\checkmark$ & -- \\
\hline Statistical analysis & -- & -- & $\checkmark$ \\
\hline
\end{tabular}

\section{Acknowledgement}

Dr. Fuyu Sun. Cangzhou Central Hospital, Nephrology, China.
Publication history

EIC: G. J. Peters, VU University Medical Center, Netherlands. Received: 19-Aug-2018 Final Revised: 05-Oct-2018

Accepted: 08-Oct-2018 Published: 25-Oct-2018

\section{References}

1. Eble J.N, Sauter G, Epstein J.I and Sesterhenn I.A. (eds) World Health Organization Classification Of Tumours. IARC Press. 2004.

2. Ljungberg B, Bensalah K, Canfield S, Dabestani S, Hofmann F, Hora M, Kuczyk MA, Lam T, Marconi L, Merseburger AS, Mulders P, Powles T, Staehler M, Volpe A and Bex A. EAU guidelines on renal cell carcinoma: 2014 update. Eur Urol. 2015; 67:913-24. | Article | PubMed

3. El Dib R, Touma NJ and Kapoor A. Cryoablation vs radiofrequency ablation for the treatment of renal cell carcinoma: a meta-analysis of case series studies. BJU Int. 2012; 110:510-6. | Article | PubMed

4. Pierorazio PM, Johnson MH, Ball MW, Gorin MA, Trock BJ, Chang P, Wagner AA, McKiernan JM and Allaf ME. Five-year analysis of a multiinstitutional prospective clinical trial of delayed intervention and surveillance for small renal masses: the DISSRM registry. Eur Urol. 2015; 68:408-15. | Article | PubMed

5. Duboule D. The rise and fall of Hox gene clusters. Development. 2007; 134:2549-60. | Article | PubMed

6. Shah $\mathrm{N}$ and Sukumar $\mathrm{S}$. The Hox genes and their roles in oncogenesis. Nat Rev Cancer. 2010; 10:361-71. | Article | PubMed

7. Chen $\mathrm{H}$ and Sukumar $\mathrm{S}$. Role of homeobox genes in normal mammary gland development and breast tumorigenesis. J Mammary Gland Biol Neoplasia. 2003; 8:159-75. | PubMed

8. Chen $\mathrm{H}$ and Sukumar S. HOX genes: emerging stars in cancer. Cancer Biol Ther. 2003; 2:524-5. | PubMed

9. Cillo C, Faiella A, Cantile $M$ and Boncinelli E. Homeobox genes and cancer. Exp Cell Res. 1999; 248:1-9. | Article | PubMed

10. Hyman E, Kauraniemi $P$, Hautaniemi S, Wolf $M$, Mousses $S$, Rozenblum E, Ringner M, Sauter G, Monni O, Elkahloun A, Kallioniemi OP and Kallioniemi A. Impact of DNA amplification on gene expression patterns in breast cancer. Cancer Res. 2002; 62:6240-5. | Article | PubMed

11. Wang $H$, Liu G, Shen D, Ye H, Huang J, Jiao L and Sun Y. HOXA1 enhances the cell proliferation, invasion and metastasis of prostate cancer cells. Oncol Rep. 2015; 34:1203-10. | Article | PubMed

12. Seifert A, Werheid DF, Knapp SM and Tobiasch E. Role of Hox genes in stem cell differentiation. World J Stem Cells. 2015; 7:583-95. | Article | PubMed Abstract | PubMed FullText

13. Domsch K, Papagiannouli F and Lohmann I. The HOX-Apoptosis Regulatory Interplay in Development and Disease. Curr Top Dev Biol. 2015; 114:121-58. | Article | PubMed

14. Platais C, Hakami F, Darda L, Lambert DW, Morgan R and Hunter KD. The role of HOX genes in head and neck squamous cell carcinoma. J Oral Pathol Med. 2016; 45:239-47. | Article | PubMed

15. Liu FT, Ou YX, Zhang GP, Qiu C, Luo HL and Zhu PQ. HOXB7 as a promising molecular marker for metastasis in cancers: a meta-analysis. Onco Targets Ther. 2016; 9:2693-9. | Article | PubMed Abstract | PubMed FullText

16. Ma R, Zhang D, Hu PC, Li Q and Lin CY. HOXB7-S3 inhibits the proliferation and invasion of MCF-7 human breast cancer cells. Mol Med Rep. 2015; 12:4901-8. | Article | PubMed Abstract | PubMed FullText 
Huiwu et al. Journal of Cancer Therapeutics \& Research 2018,

http://www.hoajonline.com/journals/pdf/2049-7962-7-2.pdf

doi: $10.7243 / 2049-7962-7-2$

17. Care A, Silvani A, Meccia E, Mattia G, Peschle C and Colombo MP. Transduction of the SkBr3 breast carcinoma cell line with the HOXB7 gene induces bFGF expression, increases cell proliferation and reduces growth factor dependence. Oncogene. 1998; 16:3285-9. | Article | PubMed

18. Care A, Felicetti F, Meccia E, Bottero L, Parenza M, Stoppacciaro A, Peschle $C$ and Colombo MP. HOXB7: a key factor for tumor-associated angiogenic switch. Cancer Res. 2001; 61:6532-9. | Article | PubMed

\section{Citation:}

Huiwu Z, Tie L and Xiuli L. Knockdown HOXB7

suppresses the proliferation, migration and invasion

in Renal cell carcinoma cells. J Cancer Ther Res. 2018;

7:2. http://dx.doi.org/10.7243/2049-7962-7-2 